\title{
INVESTIGATING THE EFFICACY OF POTENTIAL DIET-DERIVED PHYTOCHEMICALS ON LNCAP CELL LINES UNDER PHYSIOLOGICAL CONDITIONS
}

\author{
Onuoha Chinyere ${ }^{1}$, Chukwudoruo C.S. ${ }^{2}$, Ezenwaka C.O. ${ }^{3}$ and Ujowundu F.N. ${ }^{4}$ \\ ${ }^{1}$ Department of Biochemistry, School of Biological Sciences, Federal University of \\ Technology, Owerri, Imo State, Nigeria \\ E-mail: chizyonu@gmail.com \\ ${ }^{2}$ Department of Biochemistry, School of Biological Sciences, Federal University of \\ Technology, Owerri, Imo State, Nigeria \\ Email: cchukwudoruo@gmail.com \\ ${ }^{3}$ Department of Biology, Faculty of Science, Federal University Otuoke, Bayelsa State, \\ Nigeria. \\ Email: chyladyn@yahoo.com \\ ${ }^{4}$ Department of Biochemistry, School of Biological Sciences, Federal University of \\ Technology, Owerri, Imo State, Nigeria \\ Email: ujowundufn@gmail.com
}

Cite this article:

Onuoha C., Chukwudoruo

C.S., Ezenwaka C.O.,

Ujowundu F.N. (2021),

Investigating the Efficacy of

Potential Diet-Derived

Phytochemicals on LNCaP

Cell Lines Under

Physiological Conditions.

African Journal of Biology and Medical Research 4(3), 18. DOI: 10.52589/AJBMRDF4A8VSK.

\section{Manuscript History}

Received: 1 May 2021

Accepted: 21 May 2021

Published: 2 June 2021

Copyright $\odot 2020$ The Author(s). This is an Open Access article distributed under the terms of

Creative Commons Attribution-

NonCommercial-NoDerivatives

4.0 International (CC BY-NC-ND

4.0 ), which permits anyone to

share, use, reproduce and

redistribute in any medium,

provided the original author and

source are credited.
ABSTRACT: Prostate cancer $(P C a)$ is increasingly prevalent in Nigeria and chemoprevention has a potential role to stem the initiation, promotion and progression of prostate carcinogenesis. The in vivo efficacy of phytochemicals depends on bioavailability, as the concentration of the compounds reaching target sites are known to reduce tremendously. With lower concentrations being achieved in target organs, the outcome on key players of carcinogenesis needs to be understood. The effect of curcumin, 3,3'-Diindolylmethane and epigallocatechin-3-gallate were interrogated on LNCaP cell lines by imitating in vivo conditions. The LNCaP cell lines were firstly, treated with low doses of curcumin, DIM and EGCG respectively. Subsequently, to investigate chemopreventive potentials of selected phytochemicals, cell lines were pre-treated and subsequently stimulated with testosterone. Lastly, to investigate the therapeutic potential of selected phytochemicals, cell lines were pre-stimulated before receiving respective treatments. From results, the effect of low dose treatments on the androgen receptor $(A R)$ was dose-dependent. $A R$ inhibition was observed more with cell lines that received a pretreatment than cell-lines that received a pre-stimulation. All findings indicate that the investigated phytochemicals are potential chemopreventive regimens than curative regimens, since inhibitory effects on AR were enhanced more with a pre-treatment than a prestimulation. Furthermore, increased bioavailability of chemopreventive regimens will enhance efficacy.

KEYWORDS: PCa, LNCaP, Androgen Receptor, Bioavailability, Chemoprevention 


\section{INTRODUCTION}

$\mathrm{PCa}$ is diagnosed in males and is fast becoming a public health crisis in Nigeria, and around the globe [Akinremi et al., 2011; Rawla, 2019]. Early PCa cases exhibit no symptoms. Many PCa cases are categorised as demonstrating an indolent phenotype, which are usually referred to as the "pussy cats" or "slow-growers". The alternatives are the aggressive type, usually referred to as the "tigers". The latter are usually fatal [Schroeder, 1993; Rawla, 2019].

From global epidemiological data, the lowest incidences of PCa are observed in Asia and Africa. Poor awareness and low screening levels may be responsible for the reduced reported figures in Africa. However, dietary and cultural habits have been reported as being responsible for the low incidence levels in Asia [Jordan et al., 2016; Li and Sarkar, 2016; Adedeji et al., 2021]. Several studies have investigated Asian diets and some polyphenols have been identified as being potential chemopreventive regimens [Rawla, 2019]. In addition, due to the high cost of PCa management and responsive toxicity of most chemotherapeutic drugs, there is a heightened need for the study of many diet-derived agents for chemopreventive purposes.

Chemoprevention is gaining attention and is currently seen as a convenient alternative. The use of diet-derived agents for chemoprevention is due to the desire to utilise regimens that are less toxic, with little or no harmful effects, sourced from plants, not likened to "drugs", but to "food" and can be consumed over a lengthy period. In many cases, the use of diet-derived agents for chemoprevention is applicable to persons of either normal-risk, intermediate-risk or high-risk [Kelloff et al., 2000; Benetou et al., 2015]. The normal-risk group relates to healthy persons. The intermediate-risk group relates to persons exposed to harmful environmental conditions, unfavourable lifestyle habits, genetic predispositions and premalignant lesions. While the high-risk group relates to cancer patients, undergoing treatment [Kelloff et al., 2000]. Chemoprevention is greatly acceptable with individuals in the normalrisk category [Kelloff et al., 2000]. An ideal chemoprevention regimen should prevent cancer initiation and slow cancer progression [Benetou et al., 2015].

As it relates to chemoprevention, the diet-derived agents: curcumin, 3,3'-Diindolylmethane (DIM) and epigallocatechin-3-gallate (EGCG) have shown potential in the inhibition of a major key player protein, the androgen receptor [Onuoha and Anyiam, 2021]. These selected diet-derived agents are widely consumed in Asia, which is known to hold the lowest global PCa incidence levels [Rawla, 2019]. Curcumin, DIM and EGCG are polyphenol constituents of turmeric, cruciferous vegetables and green tea respectively [Ibeawuchi-Onuoha, 2016]. They are key components of Asian dishes and due to results from research studies, these cuisine-culture are been adopted in many parts of the world.

In vitro studies have generated results that show potentials of many diet-derived agents, however these investigations were conducted at the various $\mathrm{IC}_{50}$ of the diet-derived agents on investigated cells. The IC50 doses of these diet-derived agents are hardly physiologically achievable after ingestion. Detectable doses are lower in plasma, and much lower in target organs [Giordano and Tommonaro, 2019], in this case, the prostate. It is thus imperative that the efficacy of investigated diet-derived agents are investigated at much lower concentrations and at simulations that mimic in vivo conditions.

This study is focused on investigating the potential of curcumin, DIM and EGCG as chemopreventive regimens under three scenarios. The first is aimed at identifying the effect 
of low doses of curcumin, DIM and EGCG on androgen sensitive LNCaP cells. Secondly, the effect of testosterone stimulation on pre-treated $\mathrm{LNCaP}$ cells will be assessed and lastly the effect of curcumin, DIM and EGCG treatments on testosterone stimulated-LNCaP cells will be investigated. Each of these scenarios endeavours to mimic physiological conditions.

\section{METHODOLOGY}

\section{Reagents}

The phytochemicals, Curcumin, Diindolylmethane (DIM) and Epigallocathechin-3-gallate (EGCG) were purchased from Sigma-Aldrich (Germany). Primary antibodies for androgen receptor (AR), p53, Survivin and $\beta$-Actin were obtained from Santa Cruz Biotechnology (California, USA), Dako (Denmark), Novus Biological Incorporated (Colorado, USA) and Abcam (Cambridge, UK) respectively. Secondary antibodies used were anti-Rabbit IgG and anti-Mouse IgG obtained from Sigma-Aldrich (Poole, UK), donkey anti-Goat IgG obtained from Santa Cruz Biotechnology (California, USA) and Stabilized Goat anti-Mouse was obtained from Pierce (Illinois, USA).

\section{Cell culture}

The androgen-responsive human lymph node prostate carcinoma cell lines (LNCaP) were obtained from American Type Culture Collection (ATCC) (Virginia, USA). The cells were cultured in RPMI 1640 media from Invitrogen (Paisley, United Kingdom) and Sigma-Aldrich (Germany) with $10 \%$ foetal calf serum (FCS) from Invitrogen (Paisley, United Kingdom). The handling and maintenance of LNCaP cell lines have been previously described extensively in Ibeawuchi-Onuoha, 2016.

\section{Treatments of cell lines}

Treatments used were curcumin, Diindolylmethane (DIM) and Epigallocathechin-gallate (EGCG). For this procedure, large culture flasks were used. All treatments were prepared in dimethyl sulfoxide (DMSO), which constituted less than $0.1 \% \mathrm{v}: \mathrm{v}$ to culture media used. Control treatments contained equivalent concentration of DMSO and the treatment of cells was designed. The concentration doses were obtained by adjusting $\mathrm{IC}_{50}$ values from previous published works and studies for this experimental design (Shenouda et al., 2004; Garikapathy et al., 2006; Kimura et al., 2007; Valentini et al., 2009) and obtaining very low doses.

\section{To test low doses of treatments on LNCaP cells}

The LNCaP cells were treated with concentrations of curcumin $(0.5 \mu \mathrm{m}), \mathrm{DIM}(0.5 \mu \mathrm{M})$ and EGCG $(1.0 \mu \mathrm{M})$ respectively and incubated for 72 hours for each treatment round. After five rounds of treatments, the cells were trypsinised, lysed and analysed by western blotting.

\section{To test testosterone stimulation on pre-treated LNCaP cells}

$\mathrm{LNCaP}$ cells were seeded in $9 \mathrm{~cm}$ petri-dishes and left to adhere for 48 hours. The cells were then serum-starved over-night. The next day, cells were then treated with IC50 doses, $5 \mu \mathrm{M}$ curcumin, $50 \mu \mathrm{M}$ DIM and $30 \mu \mathrm{M}$ EGCG respectively for eight (8) hours. Afterwards, the cells were then stimulated with $100 \mathrm{nM}$ testosterone for a further 16 hours. Subsequently, the cells were trypsinised, lysed and analysed by western blotting. 


\section{To test respective treatments on testosterone stimulated-LNCaP cells}

LNCaP cells were seeded in $9 \mathrm{~cm}$ petri-dishes and left to adhere for 48 hours. The cells were then serum-starved over-night. The following day, the cells were then stimulated with 100 $\mathrm{nM}$ testosterone and incubated for 1 hour. Afterwards, cells were then treated with IC50 doses, $5 \mu \mathrm{M}$ curcumin, $50 \mu \mathrm{M}$ DIM and $30 \mu \mathrm{M}$ EGCG for a further 15 hours.

\section{Western blotting analysis}

Procedures to trypsinise, lyse and analyse cells by western blotting were reported extensively [Onuoha and Anyiam, 2021]. To achieve equal loading of $30 \mu \mathrm{g}$ cellular proteins for each sample aliquot, cellular proteins were determined with the use of the Bradford protein assay reagent from Biorad (Hemel Hempstead, UK). To confirm equal loading of cell samples, $\beta$ actin was used as the standardized protein.

\section{RESULTS}

In the first scenario, low doses of the diet-derived agents: curcumin, DIM and EGCG were investigated on $\mathrm{LNCaP}$ cell lines. LNCaP cell lines received a total incubation time of 360 hours (72 hours x 5) and treatment doses of $0.5 \mu \mathrm{m}$ curcumin, $0.5 \mu \mathrm{M}$ DIM and $1.0 \mu \mathrm{M}$ EGCG respectively. Cells were subsequently trypsinised, lysed and analysed by the western blotting technique. Figure 1 shows the different expressions of androgen receptors, p53 and survivin after low dose treatments of curcumin, DIM and EGCG on LNCaP cells after a long incubation time. Cells treated with $1.0 \mu \mathrm{M}$ EGCG revealed the least expression of $\mathrm{AR}$ protein, while cells treated with $0.5 \mu \mathrm{M}$ DIM revealed the most expression of AR protein. Cells treated with curcumin yielded the highest expression of p53 protein. For survivin, all treatments did not alter the pro-survival protein.

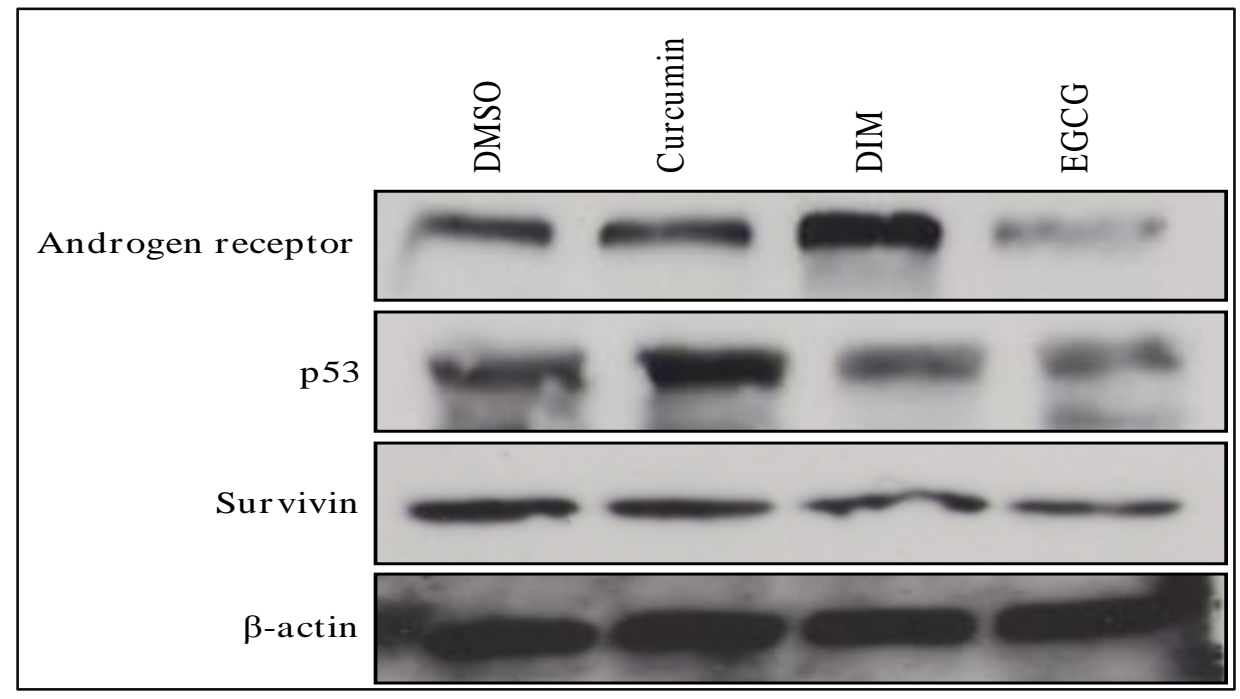

Figure 1: Effect of $0.5 \mu M$ curcumin, $0.5 \mu M$ DIM and 1.0 $\mu$ M EGCG treatments on AR, p53 and Survivin protein expressions. Treatment were at low doses, that may be physiologically achieveable. $\beta$-actin is displayed to show equal loading of cell lysate sample. 
To evaluate the effect of testosterone stimulation on 24-hour serum-starved LNCaP cells, cells were exposed to $100 \mathrm{nM}$ testosterone over a 24-hour period. The changes to AR protein expression was observed to be time-dependent (Figure 2). The AR protein was observed to have the most expression under the experimental circumstance at the 16-hour time point. This time point was used as a time reference for subsequent experiments.

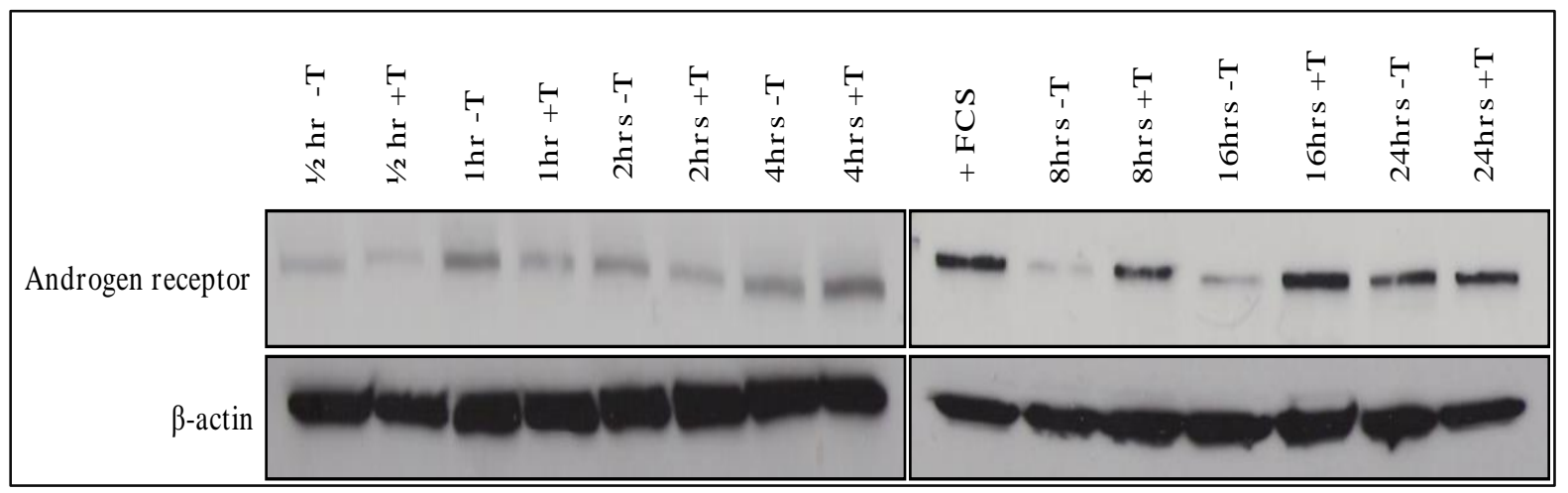

Figure 2: Effect of Testosterone stimulation on AR expression of $L N C a P$ cell line. The cells were stimulated with $100 \mathrm{nM}$ of testosterone and the response was time dependent. Without testosterone stimulation (-T) and with testosterone stimulation $(+\mathrm{T})$. $\beta$-actin is displayed to show equal loading of cell lysate sample.

Observations from the second scenario (Figure 3) reveal the effect of testosterone stimulation on pre-treated $\mathrm{LNCaP}$ cells. Here, prior to stimulation from testosterone, the cell lines receive treatments at reported $\mathrm{IC}_{50}$ doses. With this method, AR protein was not well expressed in all treatments and matching controls except for cells that were cultured with FCS. On the other hand, p53 protein is variably expressed. Cells that were pre-treated with DIM and stimulated with testosterone showed the maximum expression of $\mathrm{p} 53$.

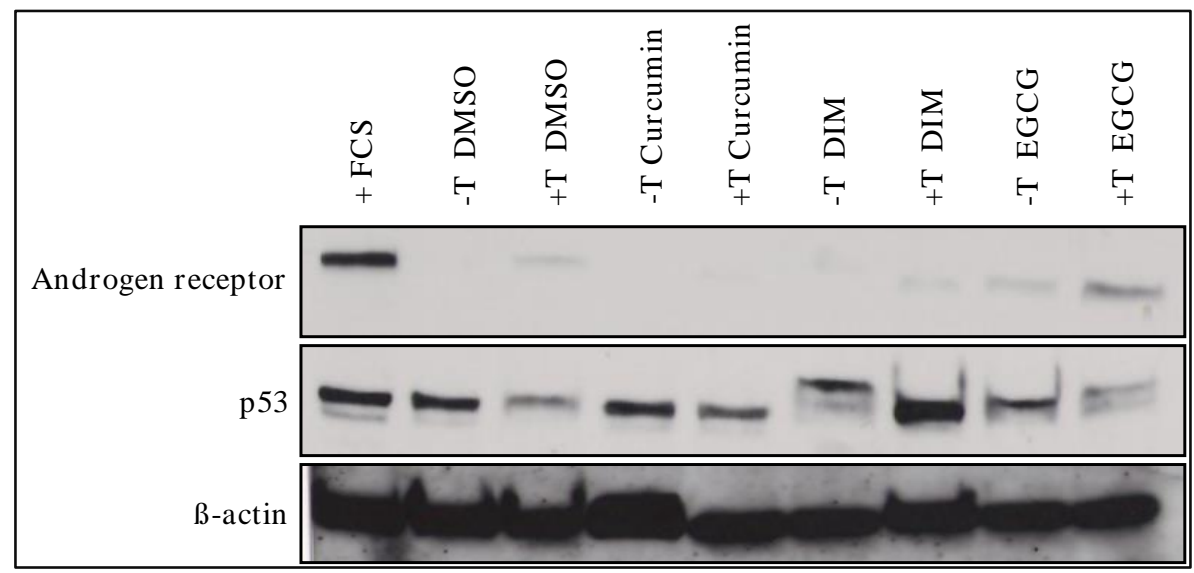

Figure 3: Effect of testosterone stimulation on pre-treated LNCaP cells, to analyse the AR and p53 expression levels of the LNCaP cell line. Treatments include $5 \mu \mathrm{m}$ curcumin, $50 \mu \mathrm{M}$ DIM and $30 \mu \mathrm{M}$ EGCG. Cells were stimulated with $100 \mathrm{nM}$ of testosterone. $(-\mathrm{T})=$ Without testosterone stimulation, $(+T)=$ with testosterone stimulation. $\beta$-actin is displayed to show equal loading of cell lysate sample. 
In the last scenario, the modality was reversed. The testosterone stimulation was conducted prior to the cell lines receiving treatment. Figure 4 reveals the effects of curcumin, DIM and EGCG on pre-stimulated LNCaP cells. The outcome on AR and p53 were investigated. Nonstimulated cells that received curcumin and EGCG treatments were observed with the least AR expression (Figure 4).

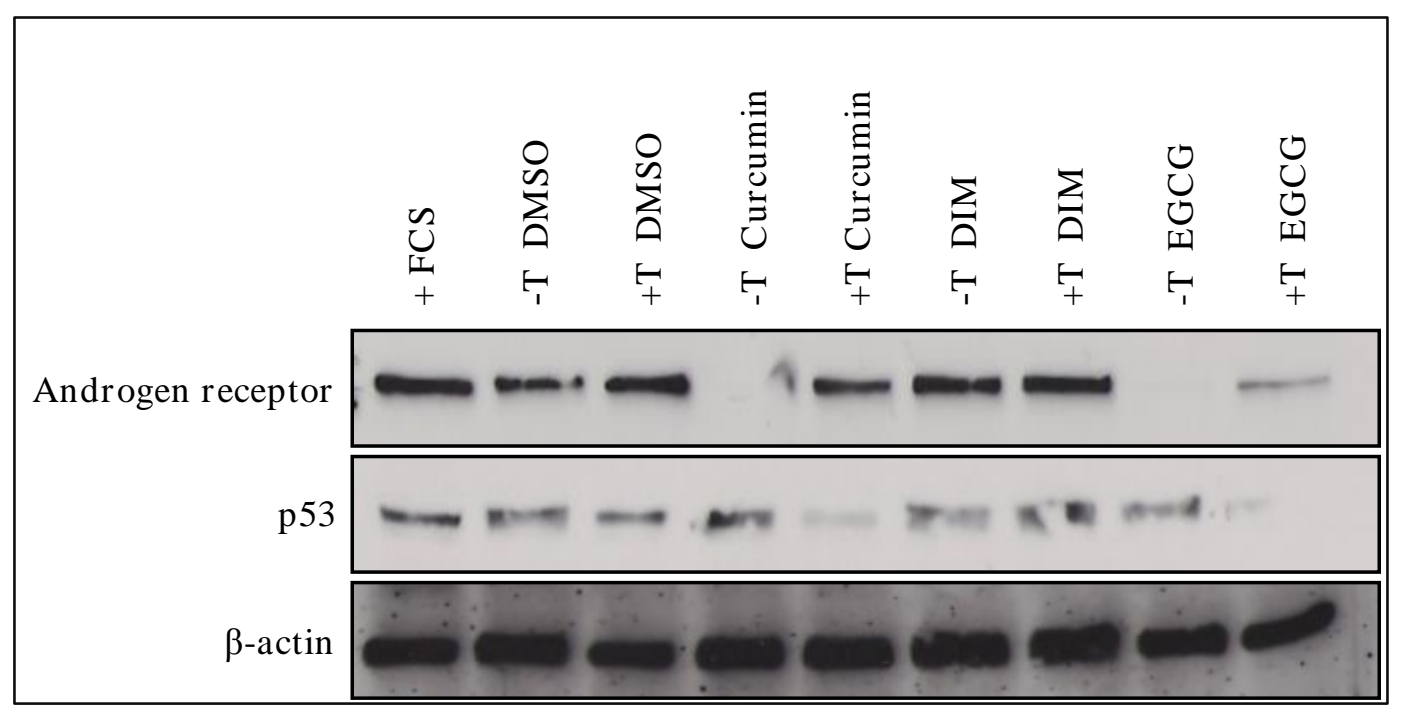

Figure 4: Effect of $5 \mu \mathrm{m}$ curcumin, $50 \mu \mathrm{M}$ DIM and $30 \mu \mathrm{M}$ EGCG treatments on testosterone stimulated LNCaP cells. To analysis the AR and p53 expression levels of the LNCaP cell line. Prior to treatment, cells were stimulated with $100 \mathrm{nM}$ of testosterone. $(-T)=$ Without testosterone stimulation, $(+T)=$ with testosterone stimulation. $\beta$-actin is displayed to show equal loading of cell lysate sample.

\section{DISCUSSION}

This study focused on investigating the effect of curcumin, DIM and EGCG on major keyplayer protein at variable experimental conditions that mimic the in vivo physiological conditions.

The use of low doses of curcumin, DIM and EGCG to treat LNCaP cell lines (Figure 1) was a strategy that imitated the post-consumption physiological concentration of the phytochemicals. It has been reported that the in vivo bioavailability of many phytochemicals are so low and unable to replicate the successes of in vitro studies [Desai et al., 2021]. The efficacy of natural or synthetic chemopreventive regimens have been found to be greatly hampered in vivo due to hydrophobicity and poor bioavailability [Desai et al., 2021]. Lower doses of curcumin, DIM and EGCG at $0.5 \mu \mathrm{M}, 0.5 \mu \mathrm{M}$ and $1.0 \mu \mathrm{M}$ respectively were investigated for their inhibitory actions on AR, p53 and survivin proteins in LNCaP cells. From results obtained (Figure 1), it was observed that the inhibitory effects of the investigated dietary agents on LNCaP cells were dose-dependent. The expression level of AR was well-reduced with EGCG treatment (Figure 1). This suggest that in vivo concentration as low as $1 \mu \mathrm{M}$ EGCG has the potential to inhibit AR protein and function. Due to the central 
role of AR to prostate carcinogenesis [Zhang et al., 2018], diet-derived agents capable of inhibiting AR function at low doses are highly sought after.

To ascertain the maximum stimulation of testosterone on LNCaP cells, cell lines were stimulated with $100 \mathrm{~nm}$ of testosterone. The maximum stimulation was observed at 16 hours time-point for AR induction (Figure 2). This time-point served as a reference in subsequent investigations. The effect of curcumin, DIM and EGCG were investigated on AR and p53 expressions, prior and subsequent to testosterone stimulation. The observed time point of 16 hours was used for testosterone stimulation. The phytochemical treatments had a stronger inhibition of AR expression when cells were pre-treated before androgen stimulation (Figure 3). However, with LNCaP cells that were pre-stimulated with androgen before treatment (Figure 4), AR inhibition was not observed. It is believed that the stimulation time of 16 hours that was allotted to the last investigation (Figure 4) may have been insufficient for the phytochemicals to cause an inhibitory effect on AR protein.

It should be noted that the experimental design of the second scenario depicts conditions that can be attributed to a pre-cancerous state. Here, the pre-treatment depicts the frequent use of the selected phytochemicals for chemopreventive purposes and the subsequent testosterone stimulation depicts heightened androgen levels in vivo due to the initiation stage of carcinogenesis. In the third scenario, the therapeutic potential of the selected phytochemical is investigated for a progressive state of PCa. Here, the pre-stimulation of cell lines depicts progressive carcinogenesis and with the subsequent treatment of cell lines, the motive was to observe any inhibition to AR.

\section{CONCLUSION}

It is imperative to state that this study highlights the chemopreventive potentials of investigated phytochemicals and exposes poor bioavailability as a major shortcoming to favourable outcomes. Efficacy of many potential chemopreventive regimens can be improved with the involvement of novel carrier molecules to target organs.

\section{REFERENCES}

Adedeji, I. A., Lawal, S. A., Aluko-Arowolo, S., and Oduwole, E. O. (2021). Men in rural Nigeria have a poor perception of prostate cancer risk; hence they seldom seek screening. Psycho-Oncology.

Akinremi, T. O., Ogo, C. N., and Olutunde, A. O. (2011, December). Review of prostate cancer research in Nigeria. In Infectious agents and cancer (Vol. 6, No. 2, pp. 1-4). BioMed Central.

Benetou, V., Lagiou, A., and Lagiou, P. (2015). Chemoprevention of cancer: current evidence and future prospects. F1000Research, 4(F1000 Faculty Rev).

Desai, P., Thumma, N. J., Wagh, P. R., Zhan, S., Ann, D., Wang, J., and Prabhu, S. (2020). Cancer chemoprevention using nanotechnology-based approaches. Frontiers in pharmacology, 11 . 
Garikapaty, V. P., Ashok, B. T., Tadi, K., Mittelman, A., and Tiwari, R. K. (2006). Synthetic dimer of indole-3-carbinol: Second generation diet derived anti-cancer agent in hormone sensitive prostate cancer. The Prostate, 66(5), 453-462.

Giordano, A., and Tommonaro, G. (2019). Curcumin and cancer. Nutrients, 11(10), 2376.

Ibeawuchi-Onuoha, C. (2016). Combinations of selected dietderived agents show enhanced growth inhibition of LNCaP cell lines. International Journal, 2(1), 20-25.

Jordan, B. C., Mock, C. D., Thilagavathi, R., and Selvam, C. (2016). Molecular mechanisms of curcumin and its semisynthetic analogues in prostate cancer prevention and treatment. Life Sciences, 152, 135-144.

Kelloff, G. J., Crowell, J. A., Steele, V. E., Lubet, R. A., Malone, W. A., Boone, C. W., ... and Sigman, C. C. (2000). Progress in cancer chemoprevention: development of dietderived chemopreventive agents. The Journal of nutrition, 130(2), 467S-471S.

Kimura, K., Itakura, Y., Goto, R., Tojima, M., Egawa, N., and Yoshihama, M. (2007). Inhibition of 17alpha-hydroxylase/C17,20-lyase (CYP17) from rat testis by green tea catechins and black tea theaflavins. Bioscience, Biotechnology, and Biochemistry, 71(9), 2325-2328.

Li, Y., and Sarkar, F. H. (2016). Role of BioResponse 3,3'-diindolylmethane in the treatment of human prostate cancer: Clinical experience. Medical Principles and Practice: International Journal of the Kuwait University, Health Science Centre, 25 Suppl 2, 1117.

Onuoha, C., and Anyiam, I. V. (2021). Western blotting evaluation of LNCaP cells in response to selective phtochemical treatments. African Journal of Biology and Medical Research, 4(2), 1-12.

Rawla, P. (2019). Epidemiology of prostate cancer. World journal of oncology, 10(2), 63.

Schröder, F. H. (1993). Prostate cancer: to screen or not to screen?. BMJ: British Medical Journal, 306(6875), 407.

Shenouda, N. S., Zhou, C., Browning, J. D., Ansell, P. J., Sakla, M. S., Lubahn, D. B., and MacDonald, R. S. (2004). Phytoestrogens in common herbs regulate prostate cancer cell growth in vitro. Nutrition and Cancer, 49(2), 200-208.

Valentini, A., Conforti, F., Crispini, A., De Martino, A., Condello, R., Stellitano, C., ... and Pucci, D. (2009). Synthesis, oxidant properties, and antitumoral effects of a heteroleptic palladium (II) complex of curcumin on human prostate cancer cells. J.Med.Chem, 52(2), 484-491.

Zhang, Y., Pitchiaya, S., Cieslik, M., Niknafs, Y. S., Tien, J. C., Hosono, Y., ... and Chinnaiyan, A. M. (2018). Analysis of the androgen receptor-regulated lncRNA landscape identifies a role for ARLNC1 in prostate cancer progression. Nature Genetics, 50(6), 814-824. 